\title{
Contraponto audiovisual? De Eisenstein a Chion'
}

\section{Audiovisual counterpoint? From Eisenstein to Chion}

Luíza Beatriz Alvim

Doutora em Comunicação pela Escola de Comunicação da Universidade Federal do Rio de Janeiro (UFRJ), pós-doutoranda no Programa de Pós-Graduação em Música da UFRJ.

<luizabeatriz@yahoo.com>

\section{RESUMO}

Consideramos o termo musical "contraponto" tal como utilizado nos textos sobre cinema e teoria cinematográfica, a partir dos escritos de Sergei Eisenstein do final dos anos 1920, passando por autores como Theodor Adorno e Hanns Eisler, Siegfried Kracaeur e Jean Mitry até os estudos, de som no audiovisual, de Michel Chion. Temos como base o questionamento da possibilidade e pertinência ou não de sua aplicação às relações entre som e imagem em produtos audiovisuais, já que esta aplicação deu origem a diversos mal-entendidos, muitas vezes provocados por um uso genérico do termo. Fazemos referências a exemplos audiovisuais nos textos desses autores e acrescentamos outros, como o primeiro volume de As mil e uma noites (Miguel Gomes, 2015), Um filme como os outros (Jean-Luc Godard, 1968) e em filmes de Robert Bresson.

\begin{abstract}
We consider the musical term "counterpoint" as employed in texts about cinema and film theory since Sergei Eisenstein's writings of the end of the twenties, passing by authors such as Theodor Adorno and Hanns Eisler, Siegfried Kracaeur and Jean Mitry until the sound studies in audiovisual by Michel Chion. As a fundamental questioning we consider the possibility and pertinence or not of its application to the relationship between sound and image in audiovisual products, as that application has caused much misunderstood, often provoked by generic utilization. We refer to audiovisual examples given in the above cited authors and join others, as the 1001 nights' first volume (Miguel Gomes, 2015) and A film like others (Jean-Luc Godard, 1968) and in films by Robert Bresson.
\end{abstract}

Keywords: Counterpoint. Audiovisual. Music.

\section{Introdução}

Diversas palavras da Música ocidental foram empregadas em outros campos², como o do Cinema, o da Literatura e o da Filosofia: "contraponto",

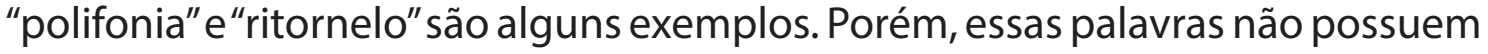
um significado único no campo de origem da Música, onde tiveram seus sentidos criados, recriados, reinterpretados e alterados ao longo dos séculos, assim como, ao chegar ao novo campo, impregnaram-se de outras interpretações.

\footnotetext{
1 Pesquisa financiada pela CAPES.

2 Usamos essa palavra no sentido elaborado por Bourdieu (2004) de um espaço estruturado de posições, constituído ao longo de um processo histórico.
} 
Todo transporte é problemático, o que já nos ensina a Teoria da Tradução, e "contraponto" é uma palavra especialmente complicada, já que, além de atravessar campos de conhecimento, faz parte de uma locução de linguagem bastante empregada. "Em contraponto" é sinônimo de "em oposição à", o que já evoca um determinado significado.

No campo dos Estudos de Cinema, o termo "contraponto" ficou célebre como meta das relações entre som e imagem no filme, desde a famosa e bastante citada Declaração sobre o futuro do cinema sonoro, de Sergei Eisenstein, Vsevolod Pudovkin e Grigori Alexandrov (Eisenstein, 2002a). Eisenstein também o empregou em diversos outros textos seus da época, muitas vezes, com um sentido de "contraste". A partir daí, "o paradigma do contraponto"- o do suposto contraste entre música e imagem - passou a ser evocado como exemplo de uma boa utilização da música no cinema (Maia, 2007). Além disso, o termo aparece em diversos textos analíticos normalmente sem qualquer contextualização e, quando há, volta a ser citado o texto-manifesto soviético.

Faremos, portanto, uma revisão teórica do uso do termo "contraponto" e outros correlatos que aparecem em textos da época de Eisenstein, como "assincronismo" e "polifonia", além da mudança nos escritos posteriores do próprio Eisenstein, em direção à busca de uma "correspondência" entre as artes. Acrescentaremos outros textos clássicos posteriores, como os de Theodor Adorno e Hanns Eisler, Siegfried Kracauer e Jean Mitry e, no campo dos Estudos do Som no Cinema, principalmente as concepções teóricas de Michel Chion.

A predominância dos textos clássicos em nosso estudo se deve ao fato de acreditarmos que a passagem da noção de contraponto para algo "já dado" em textos analíticos de objetos específicos e não mais discutível nos próprios textos teóricos recentes de som no cinema (sendo, mesmo nos escritos de Chion, restrita a poucas páginas em Audiovisão e ainda menos num livro posterior do autor, Un art sonore, le cinéma, de 2003) se deve à sua cristalização na teoria já a partir dos anos 20.

\section{Breve comentário sobre contraponto e polifonia na Música}

Ao pé da letra, "contraponto" significa que um ponto está "contra ponto" e, como mostra Sachs, na Enciclopédia Grove”, estudos sobre ele já existiam

3 SACHS, Klaus-Jürgen; DAHLHAUS, Carl. Counterpoint. In: GROVE Music Online. Disponível em: http://www.oxfordmusiconline.com Acesso em: 2 set. 2014. 
no século XIV. É importante lembrar que, na notação musical da época, eram usados literalmente pontos no lugar das figuras modernas.

Essa definição básica começou a ser flexibilizada já no século XIV, quando o contraponto começou a ser feito também com várias notas contra uma, e, no século XV, quando houve a adição de mais vozes à composição.

Nessa época, ainda não havia o pensamento vertical do acorde: no contraponto medieval e renascentista, a dimensão horizontal predomina, embora as relações verticais entre as vozes fossem também levadas em consideração. $\mathrm{E}$, nessas relações entre as vozes, o contraste (aspecto a que aludiremos bastante nesse trabalho) causado pelo uso de sons dissonantes entre si era um elemento importante para dar "maior beleza e charme" (Zarlino, 1968, p. 53), tal como lemos em tratados dos séculos XV e XVI (caso do livro de Zarlino).

Outro termo relacionado, a "polifonia" tem sido utilizada em textos extramusicais no sentido de elementos de igual importância. Porém, o termo teve significados musicais diferentes ao longo dos séculos. A rigor, a palavra latina "polifonia" quer dizer simplesmente música escrita em múltiplas partes, tal como mencionado em tratados dos séculos XIII e XIV. Wolf Frobenius observa, na Enciclopédia Grove, que o aspecto da igual importância das partes na polifonia começou a ser destacado nos tratados somente a partir do fim do século XVII.

\section{O contraponto audiovisual de Eisenstein e Pudovkin}

Em 1927, o filme americano O cantor de jazz (Alan Crosland, 1927) inaugura com sucesso (já que houve uma série de tentativas anteriores) o som sincronizado no cinema, em especial, o sincronismo da fala com a imagem dos lábios em movimento. Diante disso, importantes diretores da época como Charles Chaplin, René Clair e Sergei Eisenstein se posicionaram contra o tipo de uso do som que, efetivamente, passou a ser a norma no cinema dominante: a fala como elemento sonoro central e imagens de pessoas em diálogo, como se o cinema tivesse se tornado um "teatro filmado" (daí, os americamos chamarem esses filmes de talkies).

Então, em 1928, junto com Vsevolod Pudovkin e Grigori Alexandrov, Sergei Eisenstein publicou a Declaração sobre o futuro do cinema sonoro. Nesse sucinto manifesto, os três diretores soviéticos advogam "um uso polifônico ${ }^{4}$ do som", a

4 No original em russo, está "uso contrapuntístico". A palavra "polifonia" não aparece na declaração. 
sua "não-sincronização com as imagens visuais" e a criação de "contraponto" de imagem e som.

APENAS UM USO POLIFÔNICO do som com relação à peça de montagem visual proporcionará uma nova potencialidade no desenvolvimento e aperfeiçoamento da montagem.O PRIMEIRO TRABALHO EXPERIMENTAL COM O SOM DEVE TER COMO DIREÇÃO A LINHA DE SUA DISTINTA NÃO-SINCRONIZAÇÃO COM AS IMAGENS VISUAIS. E apenas uma investida deste tipo dará a palpabilidade necessária que mais tarde levará à criação de um CONTRAPONTO ORQUESTRAL das imagens visuais e sonoras (Eisenstein; Pudovkin; Alexandrov, 2002a, p. 226, grifo do autor).

A grande divulgação deste texto em separado nos cursos de Cinema levou a uma enorme confusão, como observou Guilherme Maia (2007) em sua tese de doutorado. Afinal, o "contraponto orquestral das imagens visuais e sonoras" aparece praticamente como sinônimo de "contraste" e o texto nos dá a entender que ele seria obtido pela "assincronia" dos elementos. Mas o que significaria essa assincronia na época? Um som fora de sincronia com a imagem, um som de outra coisa que não o representado pela imagem?

É Pudovkin (1960) quem nos esclarece num de seus textos sobre realização cinematográfica. Som "assincrônico", como podemos entender a partir de seus exemplos, é sinônimo de "som fora de quadro". Isso acontece, por exemplo, numa situação extremamente simples no cinema, quando o som precede a imagem num diálogo (ouve-se a voz da resposta do interlocutor antes de se ver a sua imagem).

Porém, é o mesmo Pudovkin que, refletindo sobre a música, considera que ela "nunca deve ser acompanhamento no filme sonoro. Ela deve reter sua própria linha"5 (Pudovkin, 1960, p.190, grifo do autor, tradução nossa). O diretor exemplifica essas afirmações com uma sequência de seu filme Deserter (1933), em que vemos, inicialmente, uma avenida movimentada, a seguir, a aproximação de uma manifestação de trabalhadores, a batalha deles contra a polícia, com a vitória inicial dos policiais, que reduzem a bandeira dos trabalhadores a frangalhos e os prendem, até que a bandeira é de novo erguida e uma nova multidão se forma.

5 No original: must in sound film never be the accompaniment. II must retain its own line. 
Pois, ao invés de usar a música para marcar cada mudança de clima da sequência, Pudovkin sugeriu ao compositor Shaporin "a criação de uma música, cujo tema emocional dominante seria durante toda a sua duração a coragem e, certamente, a vitória final. Do começo ao fim a música deve se desenvolver num crescente gradual de poder"6 (Pudovkin, 1960, p.192, itálicos originais, tradução nossa), e, desta forma, ao já estar numa forma de marcha de guerra desde o início relativamente anódino da sequência (o movimento dos carros na rua) e ter um caráter de "vitoriosa exaltação" (Pudovkin, 1960, p.192) quando os trabalhadores são derrotados, o"som lembra ao público que, a cada derrota, o espírito de luta recebe novo ímpeto para a batalha pela vitória final no futuro"7 (Pudovkin, 1960, p.193, tradução nossa). Só no fim da sequência, é que o "espírito [da música] coincide com o das imagens"8 (Pudovkin, 1960, p.192, tradução nossa). Numa avaliação final dessa sequência como um todo, Pudovkin conclui que tal seria um exemplo de "contraponto" do som com a imagem.

Seria a esse sentido de "contraponto", mais próximo daquele de "polifonia" da igual importância das partes, que Pudovkin se referira na declaração conjunta com Eisenstein e Alexandrov? Ele afirma, num capítulo posterior, que "cada faixa de som, fala ou música deve se desenvolver inalterável, enquanto as imagens vêm e vão numa sequência de planos curtos ou, então, durante imagens de duração mais longa, a banda sonora pode mudar independentemente, num ritmo próprio"9 (Pudovkin, 1960, p.196, tradução nossa), e, mesmo, que "um elemento separado do contraponto; tanto som quanto imagem preservam sua própria linha"10 (Pudovkin, 1960, p. 200, tradução nossa).

Certamente, a música não acompanha o tempo todo o sentido emocional da sequência de Deserter, não é o que Michel Chion (2011) chamou de "música empática". No entanto, o "contraponto" aí reivindicado por Pudovkin deve ser considerado em relação às convenções musicais vigentes e às expectativas do público em relação ao acompanhamento musical das imagens (voltaremos a essa questão mais adiante).

6 No original: the creation of a music the dominating emotional theme of which should throughout be courage and the certainty of ultimate victory. From beginning to end the music must develop in a gradual growth of power.

7 No original: [The] sound reminds the audience that with every defeat the fighting spirit only receives new impetus to the struggle for final victory in the future.

8 No original: does its spirit coincide with that of the image.

9 No original: Every strip of sound, speech, or music may develop unmodified while the images come and go in a sequence of short shots, or, alternatively, during images of longer duration the sound strip may change independently in a rhythm of its own.

10 No original: a separate element of counterpoint; both sound and image preserve their own line. 
No caso de Eisenstein, em outros de seus textos reunidos na coletânea A forma do filme, o diretor volta às ideias de "contraponto". Em Fora de quadro e Dramaturgia da forma do filme, ambos escritos em 1929, ele afirma que o princípio fundamental de qualquer arte é o conflito (Eisenstein, 2002a). Ele enumera uma série desses conflitos presentes no plano cinematográfico: conflito gráfico, conflito de planos, conflito de volumes, conflito espacial, conflito de luz, etc. Eisenstein chega à conclusão que o princípio significativo deles é o do "contraponto ótico", mas que, com a chegada do som, terão que enfrentar um outro "problema de contraponto: o conflito, no filme sonoro, entre acústica e ótica" (Eisenstein, 2002a, p. 44, grifo do autor). Ou ainda: "Conflito entre todo o complexo ótico e uma esfera bastante diferente. Assim, o conflito entre experiência ótica e acústica produz cinema sonoro, que é capaz de ser realizado como contraponto audiovisual" (Eisenstein, 2002a, p. 60, grifo do autor).

Até aí, "contraponto" continua a ser usado no sentido de "contraste". No entanto, Eisenstein se dá conta da especificidade de se juntar materiais diferentes (som e imagem) no cinema sonoro, uma "inesperada junção", tal qual o título de um de seus textos, publicado em 1928. Assim, em outros momentos, às vezes num mesmo texto, o diretor parece entender contraponto como síntese:

\footnotetext{
Em nossa "Declaração" sobre o cinema sonoro escrevemos sobre um método de contraponto de imagens visuais e auditivas combinadas. Para dominar este método, deve-se desenvolver em si mesmo um novo sentido: a capacidade de reduzir percepções visuais e auditivas a um "denominador comum" (Eisenstein, 2002a, p.31, grifo do autor).
}

Para Eisenstein, isso é o que acontece no teatro japonês Kabuki, que ele tanto admirava. Neste tipo de representação teatral, o som, o movimento e a voz não acompanham um ao outro, não são paralelos (palavra utilizada por ele no sentido de "sincrônico"), mas "funcionam como elementos de igual significância" (Eisenstein, 2002a, p.29, grifo do autor), num sentido próximo ao da polifonia musical no século XVII.

Eisenstein considera que, por conta dessa característica, o Kabuki é diferente do "conjunto sintético" da ópera, por exemplo, onde o "paralelismo de conjunto" (da orquestra, do coro e dos solistas) é reforçado pelo "paralelismo dos cenários". Pelo fato de que os textos de Eisenstein (em especial a Declaração sobre o futuro do cinema sonoro) foram tomados por diversos teóricos do cinema como o paradigma a ser seguido e sem contextualização dos termos, tal 
"paralelismo" seria algo a ser evitado, tal como se infere também dos textos de Pudovkin (1960) que evocamos anteriormente.

Assim, além de"contraponto", o termo"paralelismo", seu suposto contrário, aparece frequentemente em textos de teoria e estética do Cinema nos anos 1940 a 1960. Porém, antes de os examinarmos, vamos considerar como essas questões se manifestam em textos posteriores de Eisenstein.

\section{Eisenstein e a "correspondência audiovisual"}

Em seus textos do final da década de 1930 e início da década de 1940, reunidos na coletânea $O$ sentido do filme, Eisenstein (2002b) praticamente abandona a denominação "contraponto audiovisual" e a noção geral de conflito pela de correspondência entre as artes. Assim, para o diretor, imagem e música devem formar uma "correspondência audiovisual".

Os textos que compõem a coletânea são justamente da época em que Eisenstein passou a fazer filmes sonoros com a colaboração de Sergei Prokofiev, compositor de seus longas-metragens Alexandre Nevsky (1938) e Ivan o Terrível Parte I (1945) e Parte II (completado em 1946, mas exibido só em 1958). Em todos eles, há uma grande preocupação em se buscar a correspondência entre movimentos da imagem e os da música (Eisenstein identifica o movimento como um elemento comum às duas), numa "sincronização dos sentidos" (título dado a um dos textos da coletânea).

Citando exemplos da Literatura (Puschkin, Tolstoi, os Goncourt e o famoso soneto de Rimbaud, Vogais), da pintura (quadros de Leonardo da Vinci, El Greco, Van Gogh e da corrente expressionista alemã, O cavaleiro azul) e da música, Eisenstein (2002b) busca alcançar no cinema, na junção entre imagem e música, a tão almejada correspondência entre as artes, já considerada explicitamente por escritores e teóricos românticos como Goethe e Schlegel (cuja correspondência entre cores e vogais é transcrita por Eisenstein nas páginas 64 e 65), pelo pintor Kandinsky (do grupo O cavaleiro azul) e mesmo por estudiosos das propriedades musicais, como a correlação dos timbres das vozes e dos instrumentos de Heimholtz (Eisenstein, 2002b, p. 64).

Eisenstein compara, então, a montagem de seus filmes silenciosos com uma "partitura orquestral" e a chama de "montagem polifônica11", "na qual um plano é ligado ao outro [...] através de um avanço simultâneo de uma série múltipla de linhas, cada qual mantendo um curso de composição independente e cada qual contribuindo para o curso de composição total da sequência" (Eisenstein,

11 Nesse texto, o termo usado em russo é realmente "polifônica". 
2002b, p. 55, grifo do autor). Vemos, aqui, que desaparece a ideia dos "conflitos", sendo valorizados, por sua vez, os aspectos da multiplicidade de elementos, da sua simultaneidade, de sua independência e do sentido geral ("uma imagem única, unificadora, sonoro-visual", Eisenstein, 2002b, p. 54 ${ }^{12}$ ).

Com a adição do som sincronizado às imagens no filme sonoro, o diretor observa que essa estrutura se complica ainda mais e diz que "passamos desta imagem da partitura orquestral para a da partitura audiovisual" (Eisenstein, 2002b, p. 54, grifo nosso), marcada pela correspondência entre imagem e música, como "duas linhas", cada uma delas representando "todo um complexo de uma partitura de muitas vozes" (Eisenstein, 2002b, p. 56, itálicos originais).

Como no conceito de "audio-visão" desenvolvido muitos anos depois por Chion (2011), Eisenstein passa a destacar o fator vertical desse novo tipo de montagem (que ele chama de "montagem vertical") e toda a sua preocupação se volta para a busca de "paralelismos" (o que, a partir da leitura de seus textos anteriores, temos a tendência a acreditar que seria algo a ser evitado, mas que, agora, passa a ser o objetivo) entre os movimentos de imagens e sons ${ }^{13}$, ou seja, da"chave para a igualdade rítmica de uma faixa de música e uma faixa de imagem" (Eisenstein, 2002b, p.105, grifo do autor).

Podemos perceber essa preocupação na análise de uma sequência de seu filme Alexandre Nevsky, no texto Forma e conteúdo: prática ${ }^{14}$ (Eisenstein, 2002b, p.105-145), onde observamos que os "paralelismos" vão além de uma coincidência rítmica entre planos cortados no ritmo da música, como o diretor explicara no texto Sincronização dos sentidos, também presente na coletânea:

\footnotetext{
É importante ter em mente que nossa concepção de sincronização não presume coincidência. Nessa concepção existem plenas possibilidades para a execução de ambos, "movimentos" correspondentes e não-correspondentes, mas em qualquer dos casos a relação deve ser controlada composicionalmente (Eisenstein, 2002b, p. 60, grifo do autor).
}

12 O diretor volta aqui à ideia de "síntese".

13 Na verdade, esse "paralelismo" de movimentos entre imagem e música já ocorria nos filmes silenciosos de Eisenstein por conta da música composta por Edmund Meisel. Por exemplo, em 0 encouraçado Potemkin (1925), que teve o acompanhamento de Meisel apresentado pela primeira vez na estreia do filme na Alemanha (Eisenstein chegou a se corresponder e a se encontrar com Meisel, embora não saibamos o seu real controle sobre a escrita dessa partitura). Ford (2011) considera que Meisel foi um precursor de técnicas de paralelismo entre imagem e som, bastante empregadas por compositores de música para filmes sonoros na década seguinte.

14 Este texto é a terceira parte do ensaio Montagem vertical, publicadoem janeiro de 1941. 
De todo modo, para além de uma coincidência pura e simples, buscam-se "correspondências audiovisuais". É o caso da sequência analisada de Alexandre Nevsky, que começa com a preparação para a batalha contra os cavaleiros teutônicos e com o intertítulo "5 de abril de 1242".

Eisenstein se adianta a críticas e reconhece que está lidando com elementos diferentes, som e imagem. Defende-se, porém, com argumentos relacionados à percepção humana, como o movimento do olho num quadro da esquerda para a direita, semelhante ao movimento sequencial de uma partitura musical. Faz, então, um gráfico (Figura 1) representando os gestos tanto musicais (por exemplo, o acorde inicial da música, que funciona como uma "plataforma de lançamento") quanto dos movimentos do olho ao longo do quadro (por exemplo, que passa do personagem em primeiro plano, semelhante ao primeiro acorde, para a fileira de soldados indo para a profundidade do plano e à direita).

Figura 1 - Esquema de Eisenstein para o movimento dos olhos e gestos musicais

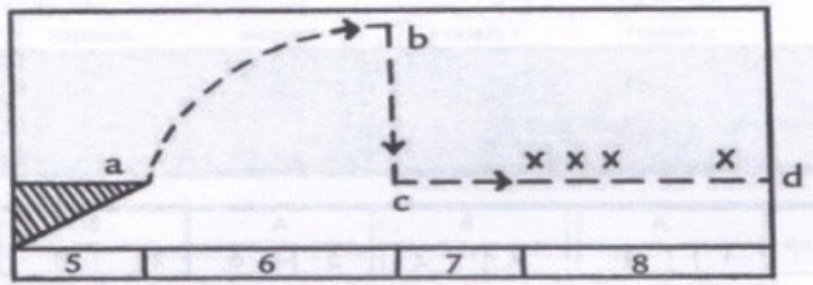

Fonte: Eisenstein, 2002b, p. 117.

Nesta sequência, alternam-se, nem sempre coincidindo com a troca de planos, duas frases musicais de Prokofiev, cada uma com dois compassos. Assim, num esquema mais completo, Eisenstein inclui cada plano do filme, as frases musicais de Prokofiev, um diagrama de composição das imagens e o já referido diagrama do movimento (Figura 2): 
Figura 2 - Início do esquema completo de imagem e música em Alexandre Nevsky

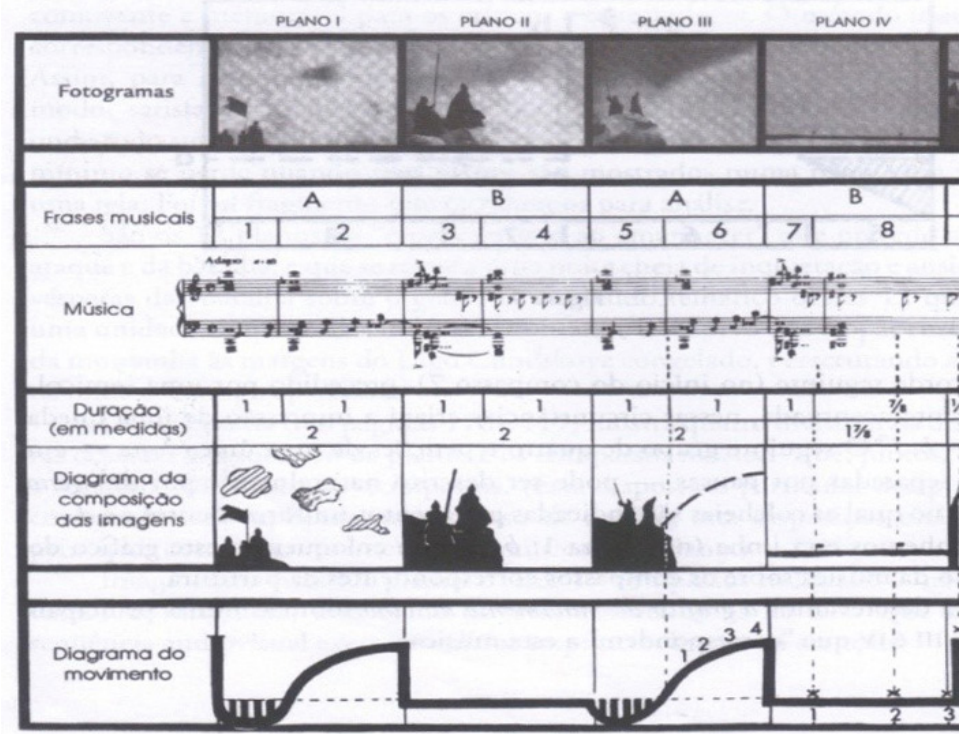

Fonte: Eisenstein, 2002b, p.118.

No entanto, tal alegado "paralelismo da música" de Prokofiev com as imagens de Alexandre Nevsky foi bastante criticado por Adorno e Eisler (1972) ${ }^{15}$, pois eles observam que esse paralelismo não existe e que Eisenstein estava considerando a música apenas como algo diagramado na partitura. Segundo os autores, o movimento (tal como evocado por Eisenstein) é uma noção ambígua, que compreende também o "ritmo geral", algo só possível de traduzir em imagens "por analogias muito vagas e pouco comprobatórias"16 (Adorno; Eisler, 1972, p. 77, tradução nossa). Além do mais, para Adorno e Eisler, o paralelismo entre imagem e música não seria algo desejável, como veremos a seguir.

\section{Paralelismo, contraponto e assincronia na teoria cinematográfica}

Depois da circulação dos textos de Eisenstein, vários autores como Theodor Adorno e Hanns Eisler, Siegfried Kracauer e Jean Mitry retomaram as

15 O livro foi escrito pelos dois autores em 1944, quando ambos estavam nos Estados Unidos, e chegou a ter uma versão em inglês, em 1947, em que figurava apenas o nome de Eisler e com reduções do texto. Tivemos acesso à versão francesa do livro, publicada em 1972, traduzida a partir da versão lançada na Alemanha, em 1969, já com a inclusão do nome de Adorno e retomando a versão original, de 1944.

16 No original: "par analogies très vagues et peu probantes". 
reflexões sobre "paralelismo", "contraponto" e "assincronia" do som e da música no cinema.

Já no anos 1940, Adorno e Eisler (1972) advogam o "contraponto dramático": "a música, ao invés de se limitar à imitação convencional do acontecimento representado ou da atmosfera deste, pode fazer surgir o sentido da cena ao se colocar ela mesma em contraste com os fatos aparentes"17 (Adorno; Eisler, 1972, p. 36-37, grifo nosso, tradução nossa). Observemos que volta a ideia do "contraponto" como "contraste", algo preferível em relação à redundância de informações visuais e sonoras.

Um dos exemplos dados pelos autores é o de uma sequência do filme Kuhle Wampe (Dudow, 1932), em que vemos casas de subúrbio dilapidadas, miséria e sujeira. Adorno e Eisler observam que a atmosfera criada pela imagem é passiva e deprimente, enquanto, em contraste, a música é rápida, incisiva, operando "um tipo de choque" que "suscita mais a revolta que um abandono sentimental"18 (Adorno; Eisler, 1972, p. 37, tradução nossa). Seria, para os autores, uma oposição do movimento (na música) à calma (das imagens).

Observamos que Adorno e Eisler (1972) recuperam aí a terminologia do "choque" dos textos mais antigos de Eisenstein, ao mesmo tempo em que a noção de movimento e de calma (talvez, aí, tendo em vista a análise de Alexandre Nevsky de Eisenstein) se refere mais à atmosfera geral das imagens e sons.

No compêndio de teoria cinematográfica lançado em 1960, Siegfried Kracauer (1960) retoma os pares sincronismo/assincronismo e paralelismo/ contraponto para fazer uma classificação dos sons dos diálogos e ruídos no filme - a música é objeto de um capítulo à parte.

Em relação ao primeiro par (sincronismo/assincronismo), Kracauer se baseia na concepção de Pudovkin $(1960)^{19}$ de que o som é assincrônico quando não está sincronizado com sua fonte natural e retoma, como esclarecimento, um dos exemplos dados pelo próprio Pudovkin (1960), além de incluir entre seus exemplos a voz over do narrador invisível de um documentário.

Para o segundo par (paralelismo/contraponto), Kracauer (1960) observa que os sons e imagens podem transmitir significados paralelos, quando, por exemplo, as palavras e gestos do falante enquadrado possuem os mesmos

17 No original: la musique, au lieu de s'épuiser dans l'imitation conventionnelle de l'événement représenté ou de l'atmosphère de celui-ci, peut faire ressortir le sens de la scène en se mettant ellemême en contraste avec les faits apparents.

18 No original: une sorte de choc qui [...] suscite plus la révolte qu'un abandon sentimental.

19 A coletânea de textos de Pudovkin foi publicada, em inglês, inicialmente em 1958, mas a maioria dos textos que a compõe é de 20 a 30 anos antes. 
significados, ou podem estar "em contraponto", quando o rosto do falante denota a sua hipocrisia, que não condiz com as palavras emitidas. Mais uma vez, o termo "contraponto" está empregado em sentido de "contraste".

Observe-se, nesses exemplos, o grande destaque dado ao elemento sonoro falado. De fato, para Kracauer (1960), o fator decisivo quanto à qualidade cinemática é o papel da fala dentro do contexto: para ele, se há predominância da fala, fica-se preso à sincronização e à tendência ao "paralelismo"; se há predominância das imagens, há liberdade de se empregar diversos modos de sincronização e favorece-se o "contraponto". Kracaeur (1960) parece se dirigir, com essa teorização, contra o logocentrismo do cinema dominante, embora seus exemplos continuem se centrando na relação fala-imagem.

Assim, o teórico faz uma combinação desses pares e propõe haver quatro modos possíveis de sincronização. "Sincronismo" e "assincronismo" são os modos principais e cada um está dividido em dois tipos, "em paralelismo" ou "em contraponto". "Sincronismo com paralelismo" se refere ao exemplo já mencionado de um falante enquadrado, cujas palavras transmitem significados congruentes com sua expressão facial, enquanto o "sincronismo em contraponto", quando esses significados divergem. Já o "assincronismo com paralelismo" pode ser exemplificado pela voz over num documentário explicando o mostrado pelas imagens. O último par, o do "assincronismo em contraponto" se refere, por exemplo, às reações contrárias dos rostos dos ouvintes durante um discurso pronunciado.

Os termos "paralelismo" e "contraponto" voltam a aparecer no capítulo específico sobre a música, quando Kracaeur (1960) considera a "música comentadora" (commentative), que, na teoria atual, costumamos chamar de música não-diegética ou extradiegética: aquela que não está justificada na imagem. Para Kracauer (1960), a música comentadora atua "em paralelismo" quando duplica climas e significados das imagens que acompanha. Como exemplos de música comentadora "em contraponto", Kracauer cita tanto a possibilidade de um acorde dissonante em meio a uma cena sentimental, quanto o exemplo do filme Deserter, de Pudovkin.

Referindo-se a essas categorias de Kracaeur, a teórica Claudia Gorbman (1987), já nos anos 1980, observa que os termos "paralelismo" e "contraponto" servem pouco se estudarmos com atenção os filmes, onde, mais do que essa oposição binária, "relações de complementaridade, ou implicação mútua, são o 
que geralmente resulta entre trilha sonora e imagem"20 (Gorbman, 1987, p.145, nossa tradução).

Ainda nos anos 1960, o teórico Jean Mitry retomou a discussão em torno da utilização do termo "contraponto", referindo-se a um de seus significados musicais e destacou a centralidade da dimensão vertical nas relações entre imagem e som no cinema.

\begin{abstract}
Em última instância, com efeito, diante de qualquer imagem, qualquer música está em contraponto: ponto sonoro contra ponto visual. Mais exatamente, o contraponto é uma forma que só destaca estruturas especificamente musicais. Trata-se de duas melodias desenvolvendose paralelamente de tal modo que sua dessemelhança solicita a atenção do ouvinte pela progressão simultânea de diferentes "vozes" e não pela qualidade dos acordes ou de "instantes harmônicos", embora a relação "vertical" das duas melodias esteja conforme as leis da harmonia. É de certa maneira o desenvolvimento temporal da harmonia ou, se preferirmos, uma nova melodia criada em função das duas outras (um pouco o equivalente da montagem, mas de uma montagem que seria paralela ao invés de ser sucessiva, como poderia ser na polivisão).Bem entendido, de ponto a contraponto, pode haver contraste, oposição, inversão, etc. ${ }^{21}$ (Mitry, 2001, p. 342, nossa tradução).
\end{abstract}

Mitry (2001, p. 343, itálico original, tradução nossa) também discorda que o termo "contraponto" possa ser utilizado no caso de "oposição de sentimentos expressos pela música e pelo filme" 22 e sugere que a única palavra que conviria a esse efeito é "contraste" e não "contraponto". Porém, "contraponto" é um termo mais elegante que o simplório "contraste", daí, talvez, a sua permanência na

20 No original: relations of complementarity, or mutual implication, are what usually result between soundtrack and image.

21 No original: A la limite, en effet, devant $n$ 'importe quelle image, n'importe quelle musique est en contrepoint: point sonore contre point visuel. Plus exactement, le contrepoint est une forme qui ne relève que des structures spécifiquement musicales. II s'agit de deux mélodies se développant parallèlement de telle sorte que leur dissemblance sollicite l'attention de l'auditeur de par la progression simultanée de différentes 'voix' et non de par la qualité des accords ou des 'instants harmoniques', bien que la relation'verticale' des deux mélodies soit conforme aux lois de I'harmonie. C'est en quelque sorte de développement temporel de l'harmonie ou, si l'on préfère, une mélodie nouvelle créée en fonction des deux autres. (Un peu l'équivalent du montage, mais d'un montage qui serait parallèle au lieu d'être sucessif, comme ce pourrait l'être dans la polyvision). Bien entendu, de point à contrepoint, il peut y avoir contraste, opposition, renversement, etc.

22 No original: l'opposition des sentiments exprimés par la musique et par le film 
teoria cinematográfica sobre o som e a música. Em 1965, época da publicação do texto, Mitry (2001) sugere

resguardar de utilizar esta expressão, hoje demasiadamente usada e desgastada, de que a música deve criar com a imagem uma espécie de "contraponto". A palavra é erudita e tem um bom efeito nos artigos de revistas. Seu emprego, no entanto, não é menos inoportuno, sendo o sentido que lhe é dado um contrassenso.. ${ }^{23}$ (Mitry, 2001, p. 342, tradução nossa).

A julgar pela perpetuação do termo de forma já cristalizada nos artigos e livros depois disso, essa argumentação não teve muito efeito.

\section{Mas, afinal, seria possível fazer um contraponto audiovisual?}

Em 1990, período em que há um grande desenvolvimento de pesquisas sobre o som no cinema (na verdade, já iniciado na década anterior, com a publicação de dossiês e livros de autores importantes do campo, como Claudia Gorbman e o próprio Chion com o seu Le son au cinéma), Michel Chion lança o livro L'audio-vision (no original em francês) e, nele, vai se debruçar também sobre a noção do "contraponto", analisando a sua possibilidade de existência no audiovisual.

No subcapítulo A questão do horizontal e do vertical, Chion (2011), como já fizera Mitry (2001), evoca os conceitos de harmonia e de contraponto da Música, destacando a dimensão horizontal do contraponto e a vertical da harmonia, lembrando, no entanto, que essas duas dimensões são difíceis de serem dissociadas na totalidade, tal como mostrado no verbete "Contraponto" de Sachs e Dahlhaus da Enciclopédia Grove.

A partir disso, Chion (2011) considera, como Mitry (2001), que "contraponto audiovisual" seria um contrassenso, pois, no cinema, as relações harmônicas e verticais (quer sejam consonantes, dissonantes ou nem uma coisa nem outra, como observa o autor) são muito mais evidentes que relações horizontais e contrapuntísticas. Para Chion (2011), muitos exemplos dados como "contraponto" no cinema seriam, no seu entender, casos do que poderia ser chamado de "harmonia dissonante", "uma vez que mostravam apenas uma

23 No original: [Nous nous] garderons d'utiliser cette expression aujourd'hui galvaudée, à savoir, que la musique doit créer avec l'image une sorte de 'contrepoint'. Le mot est savant et fait très bien dans les articles de revues. Son emploi n'en est pas moins fâcheux, le sens qu'on lui prête étant un contresens. 
discordância pontual entre uma imagem e um som relativamente à sua natureza figurativa" (Chion, 2011, p. 36).

Mais ainda, o conceito já tem um problema de base, pois, como lembra Chion (2011), todas as vozes do "contraponto musical" são constituídas pelo mesmo material, ou seja, sons musicais, enquanto o suposto "contraponto audiovisual" é constituído por categorias sensoriais diferentes: som e imagem ${ }^{24}$. Vê-se, aí, os limites da metáfora. Aplicar "contraponto" ao cinema é "mais um 'enxerto' resultante de uma especulação intelectual do que um conceito vivo" (Chion, 2011, p. 36).

Chion (2011) observa que a referida independência horizontal entre som e imagem (o que Eisenstein dissera a respeito de sua "igual significância" ou as considerações de Pudovkin sobre a sequência de seu filme Deserter) ocorreria só em alguns produtos audiovisuais, como no videoclipe, em que há cadeias paralelas de imagens e sons sem, necessariamente, uma relação precisa. Mesmo assim, o autor chega à conclusão de que, mesmo no videoclipe, há uma grande "solidariedade perceptiva", marcada por alguns pontos de sincronização ${ }^{25}$, que destacariam também a sua estrutura harmônica.

Para o autor, um exemplo mais claro de "contraponto audiovisual", se é que assim poderia ser chamado, são as transmissões televisivas de certos acontecimentos esportivos, como, por exemplo, quando são mostradas imagens mudas de ciclistas vistos de um helicóptero e o som corresponde às vozes de comentários de jornalistas, que não se referem especificamente ao momento mostrado na imagem, mas sim à prova esportiva como um todo. De qualquer modo, a circunstância do ciclismo dá sentido geral à junção desses universos imagético e sonoro.

Percebemos também dois exemplos semelhantes a esse de Chion, mas vindos do cinema. Em Um filme como os outros (Un film comme les autres, Jean-Luc Godard, 1968), um grupo de operários e estudantes universitários se reúne para avaliar os recentes acontecimentos de Maio de 1968. Durante alguns momentos da conversa, filmada nos arredores de um conjunto habitacional da periferia de Paris, são sobrepostas a ela tanto imagens de diversas manifestações - algumas, inclusive, de orientação política contrária às dos estudantes -, quanto uma voz over que não comenta diretamente as imagens de arquivo. Por vezes, ouvimos também música de protesto sobre as imagens e sons da conversa. Porém,

24 Tal fato já havia percebido por Eisenstein (2002b), como vimos anteriormente, mas o diretor preferira insistir na possibilidade de correspondência entre esses materiais.

25 Um ponto de sincronização é, numa cadeia audiovisual, um momento saliente de encontro síncrono entre um momento sonoro e um momento visual (Chion, 2011, p. 51). 
também nesse exemplo, imagem, voz (do som direto da conversa), voz over e música possuem o tema geral "manifestação/revolução".

Num filme mais recente, $O$ inquieto, primeiro volume do tríptico As mil e uma noites (2015), de Miguel Gomes, em sua primeira história, ouvimos entrevistas de trabalhadores, demitidos de um estaleiro em Viana do Castelo, falando dessa situação específica, enquanto, em alguns momentos, junto com a voz over, vemos imagens documentais de festas da cidade, que não se relacionam necessariamente ao contexto de luta operária da fala, mas que não deixam de se relacionar à cidade de Viana do Castelo e de mostrarem ajuntamentos populares.

De qualquer modo, tais exemplos são muito específicos e envolvem principalmente o elemento sonoro da fala. Voltando ao texto de Chion (2011), logo depois de dar o exemplo da transmissão esportiva e percebendo o problema constante na teoria cinematográfica da associação da palavra "contraponto" com oposição ou contraste, o autor propõe, em seu lugar, o termo "dissonância audiovisual". Com efeito, muitos exemplos reivindicados como de contraponto no cinema (com o significado de contraste, como o acorde dissonante numa sequência sentimental, no exemplo de Kracauer) se remetem, na verdade, ao "sentido" geral (algo que Mitry já argumentava que não se aplicava à noção de contraponto propriamente dito) e às expectativas geradas pelas convenções cinematográficas,

pressupõe um defasamento retórico (no modo "eu devia ouvir isso, ora eu ouço isto") preestabelecido. De fato, introduz a linguagem e as suas categorias abstratas, utilizadas em termos de sim/ não, redundantes/contraditório. [...] A dissonância audiovisual é apenas um defasamento invertido da convenção e, portanto, uma homenagem a esta, encerrando-nos numa lógica binária que pouco tem a ver com o cinema (Chion, 2011, p. 37).

Curioso é que, no parágrafo seguinte, Chion (2011) volta a empregar o termo "contraponto" como possibilidade de caracterização de uma sequência de Solaris (Tarkovski, 1972), embora, aí, fuja da associação da palavra ao"contraste"26. Nessa sequência, a namorada do protagonista, morta há anos, mas encarnada na estação espacial por conta dos efeitos misteriosos do planeta vizinho, tenta se suicidar com oxigênio líquido. Em seus movimentos convulsivos, ouvimos sons

26 Chion parece aí se render ao fato de que a palavra "contraponto" já está inexoravelmente incorporada ao vocabulário de análises de filmes. 
de vidro se quebrando. Tais sons não representariam o contrário da imagem (não seriam um contraste de sentidos), mas sim uma interpretação poética da fragilidade e uma representação sonora do personagem.

O fato é que, como já observava Gorbman (1987), as relações entre som e imagem são muito complexas, muito mais do que "congruentes" ou "contrastantes" em todos os seus aspectos. O sentido pode ser até contrastante (aspecto para o qual muitos usaram e continuam usando a palavra "contraponto"), mesmo que isso já exija uma simplificação do tipo alegre-triste, mas a música pode atuar sinergicamente com outros aspectos da imagem. Por exemplo, Annabel Cohen (2014), autora da corrente cognitivista, propõe num modelo que a música é percebida pelo espectador tanto como "estrutura" quanto como "sentido" e que tais informações correm por circuitos separados. Para Cohen (2014, p. 120), as informações estruturais da música se relacionam com informações estruturais de outros campos como, por exemplo, do visual.

Pensemos, a partir daí, no filme Um condenado à morte escapou (Robert Bresson, 1956). Nele, Bresson empregou uma música religiosa (o Kyrie da Missa em dó menor de Mozart) nas sequências em que vemos prisioneiros no pátio jogando fora seus excrementos: "é uma música de oposição" como afirmou o próprio Bresson (no filme Bresson, ni vu ni connu, de François Weyergans, 1994). Ao mesmo tempo, os movimentos dos prisioneiros para cima e para baixo, subindo e descendo as escadas que levam ao pátio nas diversas sequências com a mesma música, fazem-nos pensar nas subidas e descidas das alturas das notas musicais no trecho utilizado do Kyrie (Alvim, 2013).

Uma sinergia ainda maior entre informações estruturais de imagem e música tal como proposto por Cohen (2014) pode ser vista numa sequência inicial de outro filme de Bresson, A grande testemunha (Au hasard Balthazar, 1966), em que os movimentos do balanço em que está um dos personagens está quase que "em sincronia" com os tempos fortes da música (o Andantino da Sonata D959, de Schubert) e com o "balanço" entre harmonias de I e V grau dos compassos (Alvim, 2013).

Voltando ao capítulo de Audiovisão de Chion ([1990] 2011), a conclusãoretomada em livros posteriores do autor (Chion, 2003) e que parece ser a grande motivadora de toda a reflexão anterior - é que não existe banda sonora no cinema, no sentido de que os sons de um filme, diferentemente da banda de imagem, não formam um complexo dotado de unidade interna em si, ou seja, eles não possuem uma significação autônoma.

Chion (2011) reitera com tal afirmação que, num filme, são muito mais fortes as relações verticais simultâneas (o que, para o autor, se for utilizar a metáfora musical, é a harmonia) entre som e imagem (o que proporciona uma 
audio-visão, no conceito do autor) do que aquelas que um elemento sonoro possa estabelecer com outros sons em sua sucessão.

\section{Conclusão}

A aplicação do termo musical "contraponto" à arte cinematográfica por Sergei Eisenstein não foi uniforme ao longo dos textos do cineasta, porém, a ideia que ficou e que é propagada nos cursos de Cinema é a do contraste entre som e imagem. Isso não se sustenta num exame atento dos próprios textos posteriores de Eisenstein, que advogam, no lugar do conflito, a "correspondência audiovisual", em que "paralelismo", muito mais que contraste, reforça a ação sinérgica da imagem e do som.

"Paralelismo" e "contraponto" foram termos retomados posteriormente por Eisler e Adorno e também por Kracauer, mas não dão conta da complexidade das relações entre som e imagem no audiovisual, como observou Gorbman (1987), que vão muito além de relações simplistas de sentido. Já Chion (2011), após algumas tentativas de busca da pertinência do termo "contraponto" ao audiovisual, destaca a particular importância das relações verticais entre som e imagem nesse campo.

O exemplo do "contraponto" nos alerta para os limites e problemas do emprego (na maioria das vezes metafórico) de termos em outros campos de conhecimento. Não é nossa intenção proscrever palavras, mas tendemos a seguir a sugestão de Mitry (2001) de que o termo "contraponto", por toda imprecisão e generalizações que já causou, seja evitado ou, pelo menos, melhor contextualizado em sua aplicação no campo do audiovisual. E que, na análise de som e imagem no audiovisual, as relações complexas de seus diversos elementos (formais, de sentido, puramente semânticos, etc.) sejam levadas em consideração.

\section{REFERÊNCIAS}

A GRANDE tesmunha (Au hasard Balthazar). Direção: Robert Bresson. França/ Suécia: Argos Films, Athos Films, Parc Films, 1966 (95 min).

AS MIL e uma noites: Volume 1, O inquieto. Direção: Miguel Gomes. Portugal/ França/ Alemanha/ Suíça: O Som e a Fúria, Shellac Sud, Komplizen Film, 2015 (125 min).

ADORNO, Theodor; EISLER, Hanns. Musique de cinéma. Paris: L'Arche, 1972.

ALEXANDRE Nevsky (Aleksandr Nevskiy). Direção: Sergei Eisenstein. União Soviética: 
Mosfilm, 1938, (112 min).

ALVIM, Luíza. Robert Bresson e a música. 2013. 324 f. Tese (Doutorado em Comunicação e Cultura) - Escola de Comunicação, UFRJ, Rio de Janeiro, 2013.

BOURDIEU, Pierre. Questões de Sociologia. Lisboa: Fim de Século, 2004.

BRESSON, ni vu ni connu. Direção : François Weyergans. França : 1994 [remontagem de 1965] (65 min).

CHION, Michel. Un art sonore, le cinéma. Paris: Cahiers du Cinéma, 2003.

A audiovisão: som e imagem no cinema. Lisboa: Texto \& Grafia, 2011.

L'audio-vision. Paris: Nathan, 1994.

COHEN, Annabel. Film music from the perspective of cognitive science. In: NEUMEYER, David (org.). The Oxford Handbook of Film Music Studies. Oxford: Oxford University Press, 2014.

DESERTER (Dezertir). Direção: Vsevolod Pudovkin. União Soviética: Mezhrabromfilm, 1933 (105 min).

EISENSTEIN, Sergei. A forma do filme. Rio de Janeiro: Zahar, 2002a.

O sentido do filme. Rio de Janeiro: Zahar: 2002b.

EISENSTEIN, Sergei; PUDOVKIN, Vsevolod; ALEXANDROV, Grigori. Declaração sobre o futuro do cinema sonoro. In: EISENSTEIN, Sergei. A forma do filme. Rio de Janeiro: Zahar, 2002a, p. 225-227.

. Declaração sobre o futuro do cinema sonoro (em russo). Disponível em: http:// www.lib.ru/CINEMA/kinolit/EJZENSHTEJN/s budushchee zvukovoj filxmy.txt Acesso em: 25 jul. 2016.

FORD, Fiona. The film music of Edmund Meisel (1894-1930). 2011. $346 \mathrm{f}$. Tese (Doutorado em Filosofia) - Universidade de Nottingham, 2011.

FROBENIUS, Wolf. Polyphony. In: GROVE Music Online. Disponível em: http://www. oxfordmusiconline.com Acesso em: 2 set. 2014.

GORBMAN, Claudia. Unheard melodies: narrative film music. Bloomington: Indiana University Press, 1987.

IVAN o terrível, parte I (Ivan Groznyy). Direção: Sergei Eisenstein. União Soviética: Mosfilm, 1945. (103 min).

IVAN o terrível, parte II (Ivan Groznyy. Skaz vtoroy: Boyarskiy zagovor). Direção: Sergei Eisenstein. União Soviética: Mosfilm, 1958. (88 min). 
KRACAUER, Siegfried. Theory of film: the redemption of physical reality. New York: Oxford University Press, 1960.

KUHLE Wampe. Direção: Slaten Dudow. Alemanha: Prometheus-Film-Verleih, 1932 (80 $\min )$.

MAIA DE JESUS, Guilherme. Elementos para uma poética da música do cinema: ferramentas conceituais e metodológicas aplicadas na análise da música nos filmes Ajuste final e O homem que não estava lá. 2007. 283 f. Tese (Doutorado em Comunicação) - Faculdade de Comunicação, UFBA, Salvador, 2007.

MITRY, Jean. Esthétique et psychologie du cinéma. Paris: Cerf, 2001.

O CANTOR de jazz (The jazz singer). Direção: Alan Crosland. Estados Unidos da América: Warner Bros, 1927 (88 min).

PUDOVKIN, Vsevolod. Film Technique and Film Acting. New York: Grove Press, 1960.

SACHS, Klaus-Jürgen; DAHLHAUS, Carl. Counterpoint. In: GROVE Music Online. Disponível em: http://www.oxfordmusiconline.com Acesso em: 2 set. 2014.

SOLARIS (Solyaris). Direção : Andrei Tarkovski. União Soviética: Mosfilm, 1972 (167 min).

UM CONDENADO à morte escapou (Un condamné à mort s'est échappé ou le vent souffle où il veut). Direção : Robert Bresson. França : Gaumont, 1956 (99 min).

UM FILME como os outros (Un film comme les autres). Direção: Jean-Luc Godard. França : Anouchka Films, 1968 (120 min).

ZARLINO, Gioseffo. The Art of Counterpoint. New Haven: Yale University Press, 1968.

Recebido em: 25/7/2016

Aceito em: 15/8/2016

Endereço da autora:

Luíza Beatriz Alvim <luizabeatriz@yahoo.com>

Programa de Pós-Graduação em Música da UFRJ (PPGM-UFRJ)

Edifício Ventura Corporate Towers, Av. República do Chile, n. 330, Torre Leste, $21^{\circ}$ andar

20031-170 - Rio de Janeiro (RJ) - Brasil 